\title{
Determination of Carboxybetaine Amphoteric Surfactants in Household and Cosmetic Products by High Performance Liquid Chromatography with Prelabeling
}

\author{
Yukihiro KondoH and Satoshi TaKano \\ Tochigi Research Laboratories, Kao Corporation, Ichikai-machi, Tochigi 321-34
}

\begin{abstract}
A high performance liquid chromatographic (HPLC) method is described for the determination of carboxybetaine amphoteric surfactants in commercial houssehold and cosmetic products. The surfactants are prelabeled with 4-bromomethyl-7-methoxycoumarin and then are separated by reversed phase HPLC with a gradient elution. The determination of carboxybetaines in shampoos was carried out by an internal standard method. The calibration curve was linear in the range from 0.007 to $4.6 \mathrm{nmol}$. The relative standard deviation was found to be $1.0 \%$ for $0.46 \mathrm{nmol}$ injection. By using the proposed method, carboxybetaines in commercial household and cosmetic products were determined with high sensitivity and high selectivity.
\end{abstract}

Keywords High performance liquid chromatography, carboxybetaine amphoteric surfactants, 4-bromomethyl-7methoxycoumarin, prelabeling, shampoo

Carboxybetaine amphoteric surfactants are widely used in household and cosmetic products such as shampoos. Many kinds of carboxybetaines are now commercially available; (alkyldimethylammonio)-methane carboxylate (DAMC) seems to be most frequently used. A commercial product is generally a mixture of members of a homologous series of alkyl chains composed of 8-18 carbon atoms.

Takano et al. ${ }^{1,2}$ reported a reaction gas chromatographic (GC) method for the determination of homolog distributions of DAMC and (alkyldimethylammonio)-ethane carboxylate (DAEC). This method, however, needs tedious separation procedures for the elimination of interference from other ingredients of household and cosmetic products.

On the other hand, many investigations have been reported on the analyses of surfactants by means of HPLC, since HPLC is most suitable for the analysis of nonvolatile compounds. ${ }^{3-12}$ Matsumoto et al. ${ }^{11,12}$ analyzed mixtures of several kinds of surfactants with homolog distribution by reversed phase HPLC, and also described the analysis of DAMC. However, it will be difficult to analyze carboxybetaine amphoterics in household and cosmetic products directly, since this method has poor selectivity and sensitivity because of the use of a refractive index detector. In order to detect and analyze carboxybetaines selectively, the prelabeling of a carboxylic group of carboxybetaines is considered to be the best method, since carboxybetaines have no strong UV absorption or fluorescence. Our preliminary investigation demonstrated that some prelabeling reagents of a carboxyl group such as phenacyl bromide ${ }^{13}, p$-bromophenacyl bromide ${ }^{14}$ and 4-bromomethyl-7-methoxycoumarin (BrMmc) $)^{15-17}$ could be used for the prelabeling of carboxybetaines. Among these reagents, BrMmc was chosen as the prelabeling reagent, since it was superior to others in terms of selectivity, sensitivity and simplicity of prelabeling procedure.

This paper describes the optimization of the prelabeling reaction and the chromatographic separation, and also describes the analysis of DAMC in commercial shampoos with high sensitivity and selectivity.

\section{Experimental}

\section{Apparatus}

All separations were performed with a liquid chromatograph LC-6A system (Shimadzu Co., Kyoto, Japan) which consisted of two reciprocating piston pumps, a column oven CTO-6A, a variable-wavelength UV-VIS detector SPD-6AV, a system controller SCL$6 \mathrm{~A}$ and a sample injector 7125 (Rheodyne, Berkeley, Calif., USA). Chromatograms, peak areas and retention times were obtained by using a data processor Chromatopac C-RlA (Shimadzu).

\section{Reagents}

Develosil C8-3 (Nomura Chemical Co., Seto, Japan) was used as a stationary phase; it is a porous spherical 
octylsilanized silica gel (average particle diameter 3 $\mu \mathrm{m})$. BrMmc was obtained from Wako Pure Chemicals Co. (Osaka, Japan). DAMC with alkyl chain $\mathrm{C}_{15}\left(\mathrm{C}_{15}\right.$ DAMC) was prepared by quaternization of pentadecyldimethylamine synthesized from 1-aminopentadecane (Tokyo Chemical Industry Co., Tokyo, Japan) by Leuckart reaction with sodium monochloroacetate (Wako Pure Chemicals Co.), and recrystallized from benzene. DAMC with alkyl chain $C_{12}$, $\mathrm{C}_{14}, \mathrm{C}_{16}$ and $\mathrm{C}_{18}$ were prepared by quaternization of the corresponding alkyldimethylamine (Kao Co., Tokyo, Japan) with sodium monochloroacetate, and recrystallized from acetone, benzene or a mixture of acetone and benzene. Acetonitrile for HPLC analysis grade was obtained from Kanto Chemical Co. (Tokyo, Japan). Other reagents were of analytical reagent grade.

\section{Prelabeling procedure}

To a sample containing 1-25 mg of DAMC, $5.0 \mathrm{ml}$ of $\mathrm{C}_{15}$ DAMC methanol solution $(1000 \mathrm{mg} / \mathrm{l})$ and 5.0 $\mathrm{ml}$ of $0.5 \mathrm{M} \mathrm{NaH} \mathrm{PO}_{4}-\mathrm{H}_{3} \mathrm{PO}_{4}$ buffer solution ( $\mathrm{pH}$ 3.0) are added and the resulting solution is diluted to 100 $\mathrm{ml}$ with methanol. A $0.5 \mathrm{ml}$ portion of this solution is transferred into a reaction tube with a screw cap. After methanol is completely evaporated in a gentle stream of $\mathrm{N}_{2}$ gas, $2.0 \mathrm{ml}$ of $0.25 \% \mathrm{BrMmc}$ dimethylformamide (DMF) solution is added and the reaction mixture is heated at $70^{\circ} \mathrm{C}$ for $30 \mathrm{~min}$. A $20 \mu$ portion of the resulting solution is injected into HPLC.

\section{Chromatographic conditions}

A stainless column (4.0 mm i.d., $250 \mathrm{~mm}$ long) packed with Develosil $\mathrm{C} 8-3$ was used and kept at $30^{\circ} \mathrm{C}$. The mobile phases used were $0.1 \mathrm{M}$ sodium perchlorate in acetonitrile-water $(45 / 55$, solvent $\mathrm{A})$ and $0.1 \mathrm{M}$ sodium perchlorate in acetonitrile-water $(90 / 10$, solvent B) at a flow rate of $0.8 \mathrm{ml} / \mathrm{min}$. The analysis was done according to the time program described below. The starting condition was $80 / 20$ (Solvent $A / B)$ and the solvent ratio was linearly changed from $80 / 20(\mathrm{~A} / \mathrm{B})$ to $20 / 80(\mathrm{~A} / \mathrm{B})$ for $9 \mathrm{~min}$. During the next $23 \mathrm{~min}$ the solvent ratio was linearly changed from $20 / 80$ to $10 / 90$, and then the mobile phase was changed to the starting condition, which was held for 13 min for reconditioning. The column effluent was monitored at $325 \mathrm{~nm}$.

\section{Results and Discussion}

\section{Optimization of prelabeling reaction}

Prelabeling reaction of fatty acids with BrMmc is usually effected in acetone under reflux condition in the presence of 18-crown-6-ether and potassium carbonate as catalysts. ${ }^{15-17}$ However, it was found that the reaction of carboxybetaines with $\mathrm{BrMmc}$ proceeded in the absence of the catalysts, which indicated that carboxybetaines were an inner salt. Figure 1 shows the

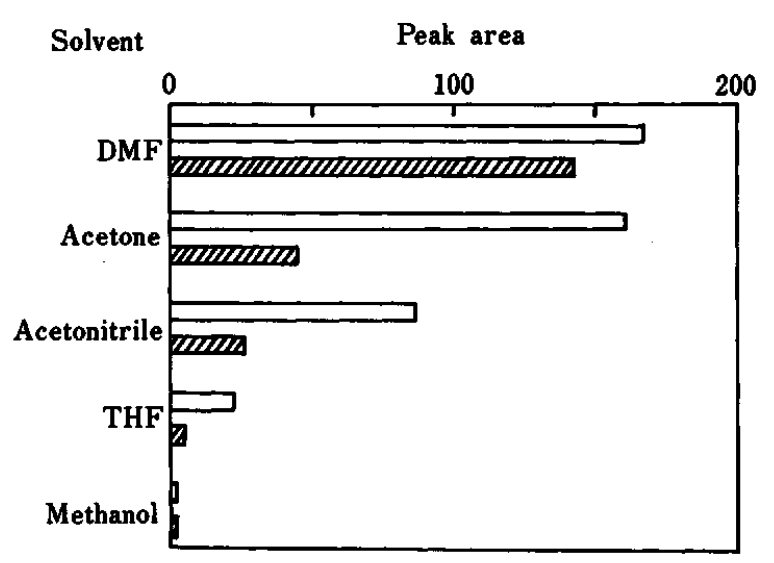

Fig. 1 Effect of reaction solvents on peak areas of $\mathrm{C}_{12}$ DAMC, $\square, 100$ ppm $C_{12}$ DAMC; DAMC $+1.0 \%$ TEA lauryl sulfate.

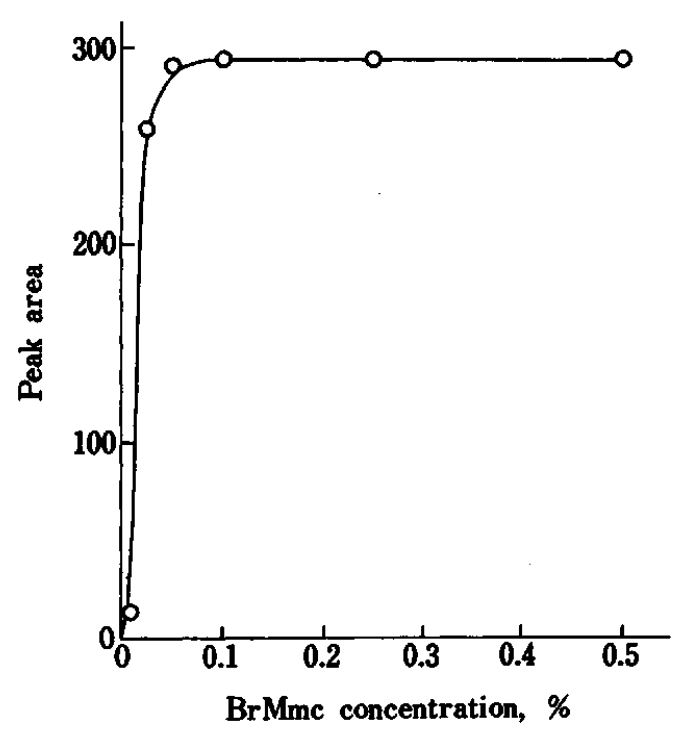

Fig. 2 Effect of concentration of $\mathrm{BrMmc}$ on peak areas of $\mathrm{C}_{12}$ DAMC.

effect of the solvents used on the prelabeling reaction of $\mathrm{C}_{12}$ DAMC. The reaction smoothly proceeded in DMF and acetone. However, some ingredients of household and cosmetic products slightly interfered with the prelabeling reaction, as will be described later. Furthermore, the extent of interference by these ingredients varied with the solvent as shown in Fig. 1, and DMF suffered the least interference. Therefore; DMF was chosen as a reaction solvent.

Figure 2 shows the effect of the concentration of BrMmc on peak areas of $\mathrm{C}_{12}$ DAMC. The peak area increases rapidly up to a concentration of $0.05 \%$ and reached a constant value at $0.1 \%$. Thus, the concentration of BrMmc was fixed at $0.25 \%$. The reaction temperature was held at $70^{\circ} \mathrm{C}$, following Hayashi et al. ${ }^{17}$ The effect of reaction time on the peak 


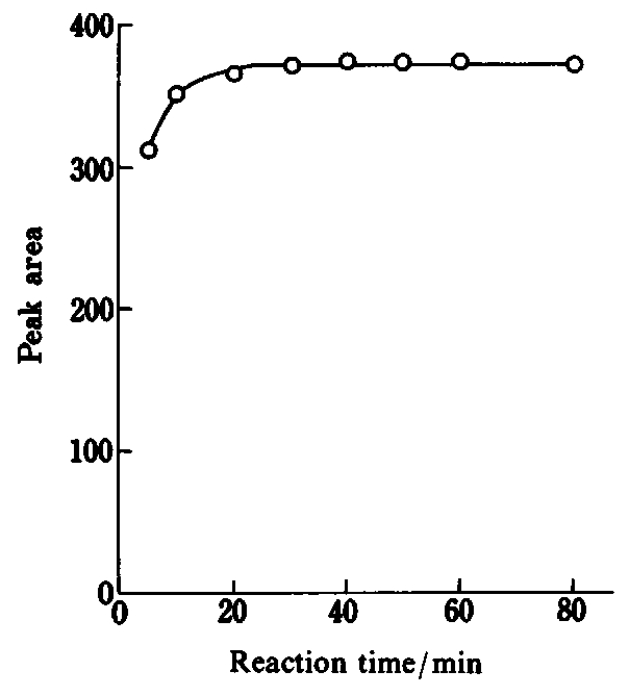

Fig. 3 Effect of reaction time on peak areas of $\mathrm{C}_{12}$ DAMC.

areas of $C_{12}$ DAMC was investigated. The results are shown in Fig. 3. Since the peak areas were almost constant above $20 \mathrm{~min}$, the reaction time was determined to be $30 \mathrm{~min}$. On the other hand, DAMC is considered to be an inner salt under the conditions where the carboxyl group of DAMC dissociates. Figure 4 shows the effect of $\mathrm{pH}$ of the prelabeling reaction on peak areas of $\mathrm{C}_{12}$ DAMC. The peak areas have almost constant values over the $\mathrm{pH}$ range of 2 to 10.

On the other hand, soap was also labeled with $\mathrm{BrMmc}$ and indicated retention behavior similar to that of DAMC. However, it was found that soap was not significantly labeled with $\mathrm{BrMmc}$ below $\mathrm{pH} \mathrm{7}$, as shown in Fig. 4, which led us to determine the $\mathrm{pH}$ of prelabeling reaction to be 3 . On the basis of these results, prelabeling procedure was determined, as described in the experimental section. In addition, other surfactants possessing a carboxyl group may be labeled with BrMmc; however, they do not interfere with the analysis of DAMC, except for imidazolinium amphoterics and sodium $N$-acyl-L-glutamate, which are rarely used with DAMC. However, the interferences from these surfactants may be eliminated by hydrolysis. ${ }^{18}$

The effect of ingredients in household and cosmetic products on the prelabeling reaction was investigated. As shown in Table 1, TEA lauryl sulfate and TEA poly(oxyethylene) lauryl ether sulfate slightly interfered with the prelabeling reaction. Therefore, $\mathrm{C}_{15}$ DAMC, which was rarely used in commercial shampoos, was chosen as an internal standard in order to cancel out the effect of the interferences.

\section{Optimization of the separation}

Under the optimum reaction conditions, soap is slightly labeled with $\mathrm{BrMmc}$ and indicates a retention

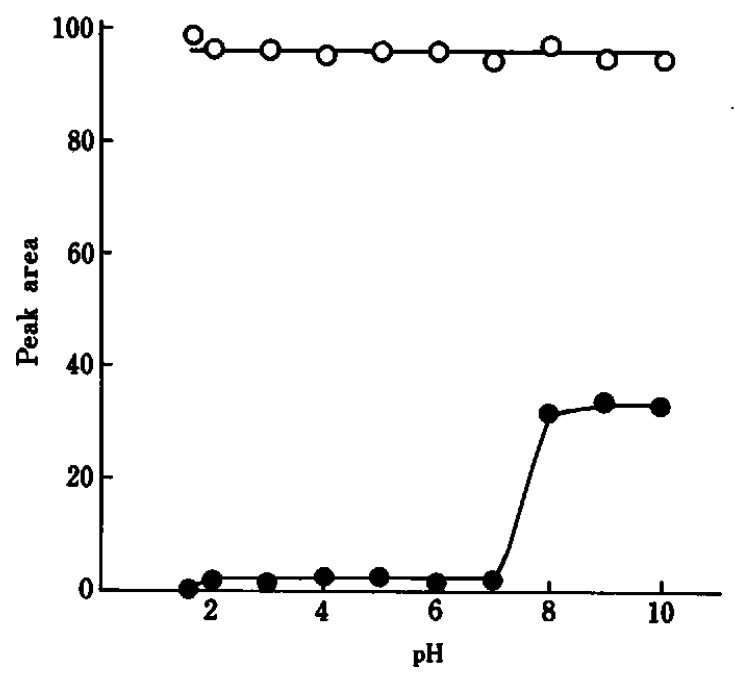

Fig. 4 Effect of pH of sample solution on peak areas of DAMC and soap. $O, C_{12}$ DAMC;,$C_{12}$ soap.

Table 1 Effect of ingredients of household and cosmetic products on the prelabeling reaction

\begin{tabular}{lcccc}
\hline \multicolumn{1}{c}{ Ingredients } & $\begin{array}{c}\text { Ingredients } \\
\text { added/ } \\
\mu \mathrm{g}\end{array}$ & $\begin{array}{c}\text { DAMC } \\
\text { present/ } \\
\mu \mathrm{g}\end{array}$ & $\begin{array}{c}\text { DAMC } \\
\text { found/ } \\
\mu \mathrm{g}\end{array}$ & $\begin{array}{c}\text { Rec, } \\
\%\end{array}$ \\
\hline $\begin{array}{l}\text { Sodium alkylbenzenesul- } \\
\text { fonate }\end{array}$ & 2500 & 50.0 & 50.5 & 101.1 \\
$\begin{array}{l}\text { Sodium } \alpha \text {-olefin sulfonate } \\
\text { Sodium lauryl sulfate }\end{array}$ & 2500 & 50.0 & 49.0 & 98.0 \\
$\begin{array}{l}\text { TEA lauryl sulfate } \\
\text { Sodium poly(oxyethylene) }\end{array}$ & 2500 & 50.0 & 49.5 & 99.0 \\
$\quad$ lauryl ether sulfate & 2500 & 50.0 & 43.2 & 86.4 \\
$\begin{array}{l}\text { TEA poly(oxyethylene) } \\
\text { lauryl ether sulfate }\end{array}$ & 2500 & 50.0 & 49.9 & 99.8 \\
$\begin{array}{l}\text { Poly(oxyethylene) alkyl } \\
\text { ether }\end{array}$ & 1250 & 50.0 & 45.9 & 91.8 \\
$\begin{array}{l}\text { Coconut diethanol amide } \\
\begin{array}{l}\text { Poly(oxyethylene glycol) } \\
\text { Alkyltrimethylammonium } \\
\text { chloride }\end{array}\end{array}$ & 1250 & 50.0 & 49.1 & 98.2 \\
$\begin{array}{l}\text { Dialkyldimethylammonium } \\
\text { chloride }\end{array}$ & 1250 & 50.0 & 50.3 & 96.6 \\
$\begin{array}{l}\text { Triethanolamine } \\
\text { Diethanolamine }\end{array}$ & 1000 & 50.0 & 49.5 & 98.9 \\
$\begin{array}{l}\text { Monoethanolamine } \\
\text { EDTA.2Na }\end{array}$ & 2500 & 50.0 & 49.1 & 98.1 \\
\hline & 2500 & 50.0 & 50.4 & 100.8 \\
\hline & 1000 & 50.0 & 49.8 & 99.5 \\
\hline
\end{tabular}

behavior similar to that for DAMC. Therefore, optimization of the separation of DAMC was investigated taking that of soap into account. Good separation of DAMC was achieved by using Develosil C8-3 as a stationary phase and aqueous acetonitrile solution containing sodium perchlorate, which was essential for good resolution of ionic surfactants ${ }^{19-21}$, as a mobile phase. Since the effects of sodium perchlorate concentration and column temperature on the separation of both compounds were less than that of water 


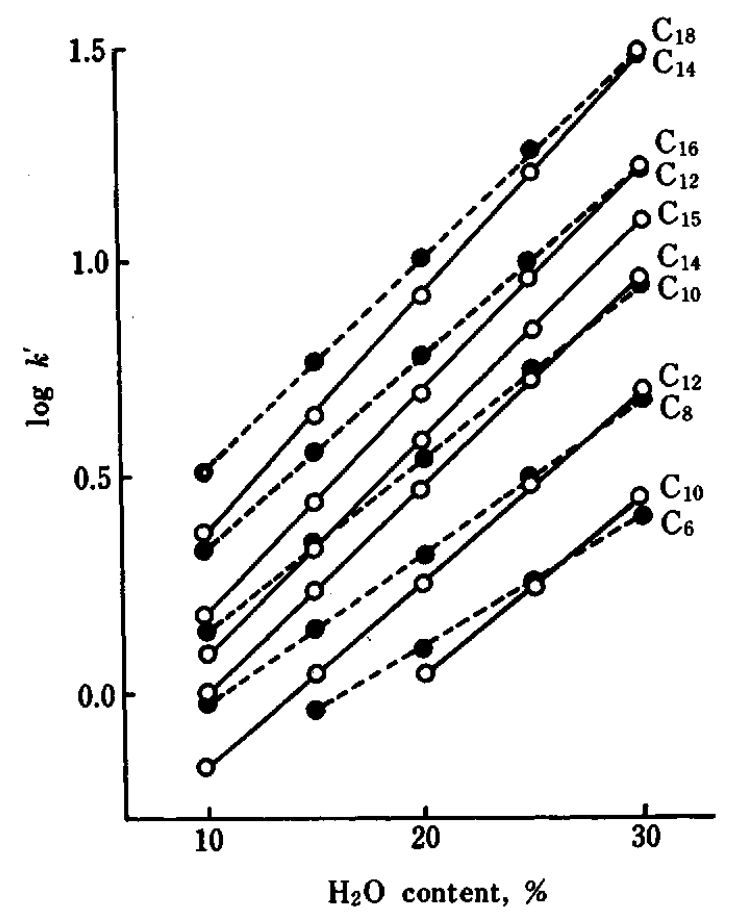

Fig. 5 Effect of water content in mobile phase on capacity factors of DAMC and soap. O, DAMC; , soap.

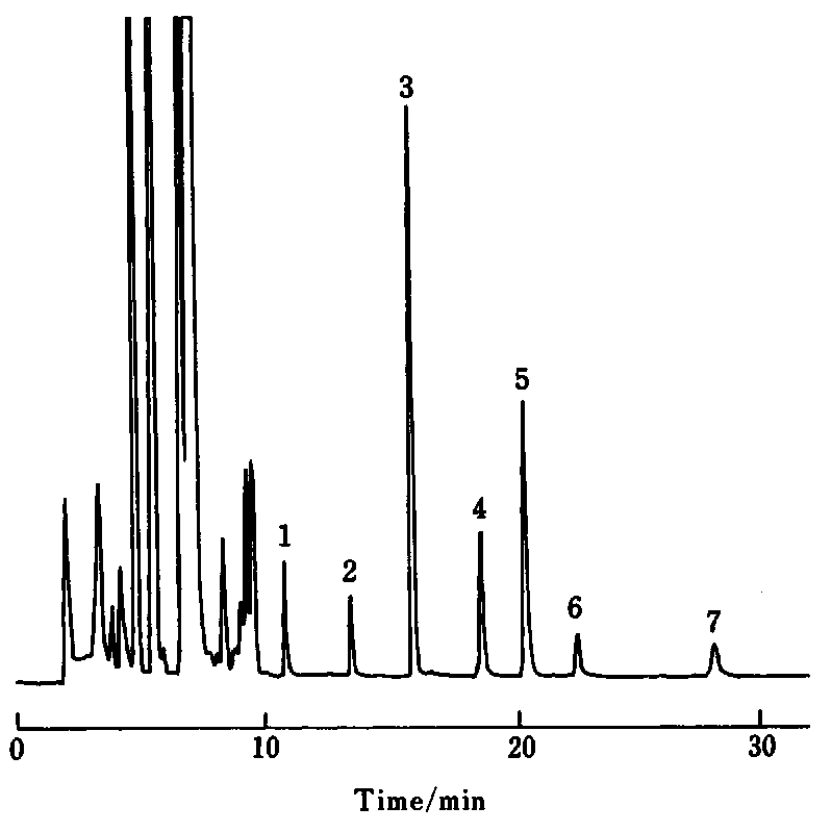

Fig. 6 Typical chromatogram of commercial DAMC. 1, $\mathrm{C}_{8} ; 2, \mathrm{C}_{10} ; 3, \mathrm{C}_{12} ; 4, \mathrm{C}_{14} ; 5, \mathrm{C}_{15}$ (an internal standard); 6, $\mathrm{C}_{16} ; 7, \mathrm{C}_{18}$.

content, the concentration of sodium perchlorate was determined to be $0.1 \mathrm{M}$ and the column temperature to be $30^{\circ} \mathrm{C}$. Figure 5 shows the effect of water content in the mobile phase on the capacity factors of DAMC and

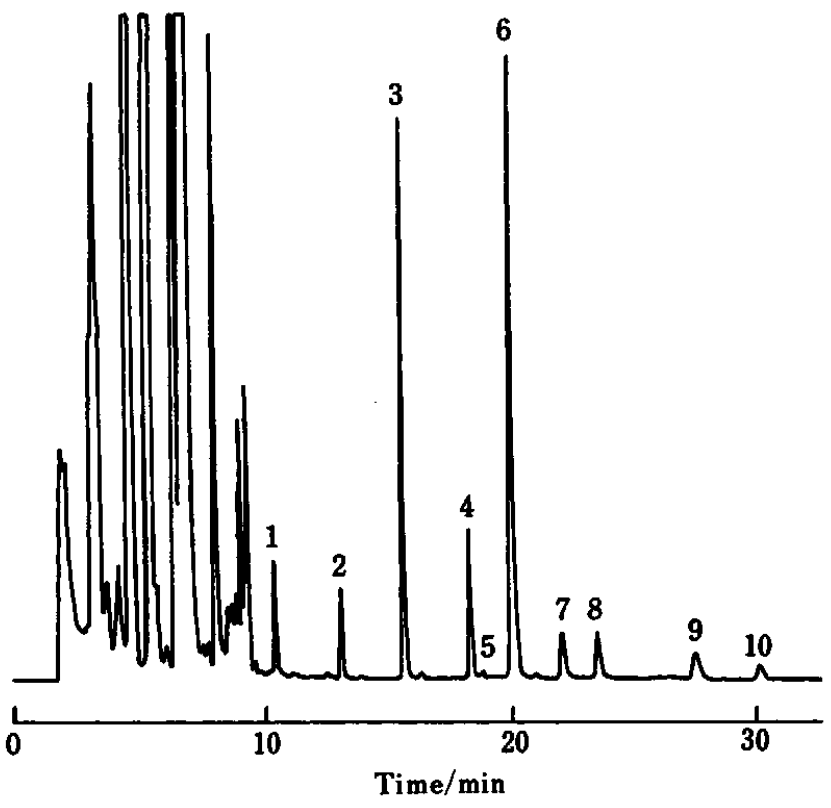

Fig. 7 Chromatogram of a mixture of commercial DAMC and soap. Soap (sodium salt, coconut/tallow $=6 / 4$ ) is added twenty times to DAMC. 1, $\mathrm{C}_{8}$ DAMC; $2, \mathrm{C}_{10}$ DAMC; 3, C 12 DAMC; 4, C 14 DAMC; 5, C 10 soap; 6, $C_{15}$ DAMC (an internal standard); 7, $\mathrm{C}_{16}$ DAMC; $8, \mathrm{C}_{12}$ soap; 9, $\mathrm{C}_{18}$ DAMC; $10, \mathrm{C}_{14}$ soap.

soap. The capacity factors increase with an increase in water content, but the slopes of DAMC slightly differ from those of soaps. Satisfactory separation of $\mathrm{C}_{10}$ $\mathrm{C}_{18}$ DAMC and $\mathrm{C}_{6}-\mathrm{C}_{14}$ soaps was obtained at $20 \%$ of the water content; however, $\mathrm{C}_{8}$ DAMC could not be separated from the peaks of the excess prelabeling reagents. On the contrary, a longer separation time was required in order to separate the peak of $\mathrm{C}_{8}$ DAMC from the reagent peaks. Thus, it seemed difficult to analyze $\mathrm{C}_{8}-\mathrm{C}_{18}$ DAMC simultaneously in an appropriate time with isocratic elution, which led us to investigate a gradient elution method. Under the optimum conditions described in the experimental section, excellent separation of $\mathrm{C}_{8}-\mathrm{C}_{18}$ DAMC was obtained without drift of baseline, as shown in Fig. 6. Figure 7 demonstrates a satisfactory separation of DAMC and soaps, though soaps are added twenty times to DAMC.

\section{Determination and relative molar response}

$\mathrm{BrMmc}$ has been used as a fluorescence prelabeling reagent of a carboxyl group. ${ }^{15-17}$ The relative molar responses of $\mathrm{C}_{16}$ and $\mathrm{C}_{18}$ DAMC to $\mathrm{C}_{15}$ DAMC with fluorescence detection were still rather low. Since the relative molar responses of DAMC with UV detection were in the range from 0.97 to 1.01 , as shown in Table 2, a UV detector was used in the present study. Table 3 shows the comparison of the homolog analysis of a commercial DAMC by the proposed method with that by the established method. ${ }^{2}$ The agreement between 
Table 2 Relative molar response of the homologs of DAMC to $\mathrm{C}_{15}$ DAMC

\begin{tabular}{|c|c|c|c|c|}
\hline \multicolumn{5}{|c|}{ Alkyl chain length of DAMC } \\
\hline$C_{12}$ & $C_{14}$ & $\mathrm{C}_{15}$ & $\mathrm{C}_{16}$ & $\mathrm{C}_{18}$ \\
\hline \multicolumn{5}{|c|}{ Relative molar response to $C_{15}$ DAMC } \\
\hline 0.98 & 1.01 & 1.00 & 0.97 & 0.97 \\
\hline
\end{tabular}

Table 3 Comparison of the result of homolog analysis of a commercial DAMC by the proposed method with that of established method ${ }^{\mathrm{a}}$

\begin{tabular}{ccc}
\hline $\begin{array}{c}\text { Alkyl chain } \\
\text { length }\end{array}$ & $\begin{array}{c}\text { Proposed method, } \\
\text { mol\% }\end{array}$ & $\begin{array}{c}\text { Established method } \\
\text { mol\% }\end{array}$ \\
\hline $\mathrm{C}_{8}$ & 10.5 & 9.3 \\
$\mathrm{C}_{10}$ & 7.0 & 7.1 \\
$\mathrm{C}_{12}$ & 52.8 & 53.4 \\
$\mathrm{C}_{14}$ & 16.3 & 16.8 \\
$\mathrm{C}_{16}$ & 6.8 & 6.6 \\
$\mathrm{C}_{18}$ & 6.7 & 6.8 \\
\hline
\end{tabular}

a. DAMC is analyzed by the reaction GC method. ${ }^{2}$

the two distributions was satisfactory.

All calibration curves of $\mathrm{C}_{12}-\mathrm{C}_{18}$ DAMC gave linear relationships in the range of 0.007-4.6 nmol. The relative standard deviation observed with five measurements was found to be $1.0 \%$ for $0.46 \mathrm{nmol}$ of $\mathrm{C}_{12}$ DAMC.

\section{Applications}

The precision and accuracy of the proposed method were tested by adding known amounts of $\mathrm{C}_{12}$ DAMC to commercial shampoos without carboxybetaines. As show in Table 4, the recoveries and reproducibilities were satisfactory. Table 5 shows the results of the analysis of carboxybetaines in commercial shampoos by the proposed method. No interference peak was recognized and satisfactory reproducibilities were demonstrated in these analyses.

The proposed method should be applicable for the analysis of DAMC in household and cosmetic products such as shampoos.

\section{References}

1. S. Takano, C. Takasaki, K. Kunihiro and $\mathbf{M}$. Yamanaka, J. Am. Oil Chem. Soc., 54, 139 (1977).

2. S. Takano, M. Kuzukawa and M. Yamanaka, J. Am. Oil Chem. Soc., 54, 484 (1977).

3. A. Nakae, K. Tsuji and M. Yamanaka, Anal. Chem., 53, 1818 (1981).

4. S. Takano, N. Yagi and K. Kunihiro, Yukagaku, 24, 389 (1975).
Table 4 Recovery of DAMC added to several commercial shampoos ${ }^{\mathrm{a}}$ by the proposed method

\begin{tabular}{cccccr}
\hline \multirow{2}{*}{ Shampoo } & \multicolumn{2}{c}{ DAMC, \% } & $n$ & RSD, \% & $\begin{array}{c}\text { Recovery, } \\
\%\end{array}$ \\
\cline { 2 - 5 } Added $^{\mathrm{b}}$ & Found & & & \\
\hline a & 1.005 & 0.990 & 4 & 1.33 & 98.6 \\
b & 1.005 & 1.010 & 4 & 0.46 & 100.5 \\
c & 1.005 & 0.999 & 4 & 1.08 & 99.4 \\
d & 1.005 & 0.987 & 4 & 0.74 & 98.2 \\
\hline
\end{tabular}

a. They included no carboxybetaines.

b. $C_{12}$ DAMC is added.

RSD, relative standard deviation.

Table 5 Determination and homolog analysis of DAMC in commercial shampoos (A-D) by the proposed method

\begin{tabular}{|c|c|c|c|c|c|c|c|}
\hline \multirow{2}{*}{\multicolumn{2}{|c|}{$\begin{array}{c}\text { Content, } \\
\%\end{array}$}} & \multicolumn{6}{|c|}{ Alkyl chain distribution, $\mathrm{mol} \%$} \\
\hline & & $\mathrm{C}_{8}$ & $C_{10}$ & $\mathrm{C}_{12}$ & $\mathrm{C}_{14}$ & $\mathbf{C}_{16}$ & $\mathrm{C}_{18}$ \\
\hline $\mathbf{A}$ & 2.3 & - & - & 76.1 & 23.9 & - & - \\
\hline B & 0.6 & - & 2.4 & 70.8 & 22.9 & 3.9 & - \\
\hline C & 5.8 & - & - & 97.6 & 2.4 & - & - \\
\hline D & 1.9 & 11.9 & 8.8 & 49.2 & 15.8 & 7.6 & 6.7 \\
\hline
\end{tabular}

5. A. Nakae, K. Kunihiro and G. Muto, J. Chromatogr., 134, 459 (1977).

6. A. Nakae and K. Kunihiro, J. Chromatogr., 156, 167 (1978).

7. D. Thomas and J.-L. Rocca, Anahusis, 7, 386 (1979).

8. M. Kudoh, H. Ozawa, S. Fudano and K. Tsuji, $J$. Chromatogr., 287, 337 (1984).

9. J. Kawase, K. Tsuji and Y. Yasuda, J. Chromatogr., 267, 149 (1983).

10. F. Smedes, C. Kraak, C. F. Werkhoven-Goewie, U. A. Th. Brinkman and R. W. Frei, J. Chromatogr., 247, 123 (1982).

11. K. Nakamura and Y. Morikawa, J. Am. Oil Chem. Soc., 59, 64 (1982).

12. K. Nakamura and Y. Morikawa, J. Am. Oil Chem. Soc., 61, 1130 (1984).

13. R. F. Borch, Anal. Chem., 47, 2437 (1975).

14. H. D. Durst, M. Milano, E. J. Kikta, S. A. Connelly and E. Grushka, Anal. Chem., 47, 1797 (1975).

15. S. Lam and E. Grushka, J. Chromatogr., 158, 207 (1979).

16. W. Voelter, R. Huber and K. Zech, J. Chromatogr., 217, 491 (1981).

17. K. Hayashi, J. Kawase, K. Yoshimura, K. Ara and K. Tsuji, Anal. Biochem., 136, 314 (1984).

18. S. Takano and K. Tsuji, J. Am. Oil Chem. Soc., 60, 874 (1983).

19. K. Nakamura, Y. Morikawa and I. Matsumoto, J. Am. Oil Chem. Soc., 58, 72 (1981).

20. J. Kawase, J. Chromatogr., 262, 293 (1983).

21. S. L. Abidi, J. Chromatogr., 324, 209 (1985).

(Received June 6, 1986)

(Accepted July 29, 1986) 